1. Introdução;

2. O debate brasileiro;

3. A comparação entre 1960 e 1970;

4. Conclusões.

\section{Distribuição da renda no Brasil: dados mais exatos e novas descobertas}

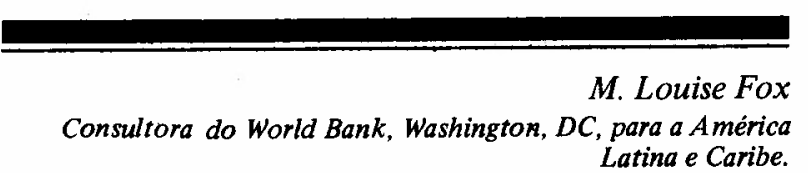

O Brasil é freqüentemente citado como o país que exemplifica a ruptura entre o crescimento econômico e a eqüidade. A base desta asserção é a desigualdade crescente na distribuição de renda entre os censos de 1960 e 1970, combinada com um crescimento da renda per capita ao longo desta década. Numerosos especialistas analisaram este periodo; no entanto, pouco ou nenhum acordo reina tanto quanto às causas, como quanto à extensão deste aparente crescimento da desigualdade. Usando a amostra realizada recentemente pelo censo demográfico de 1970 , este trabalho examina as bases empíricas desta afirmativa de deterioração da distribuição de renda ao longo da década. Os correlatos da variância de renda e pobreza são analisados aplicando-se níveis de pobreza definidos por ambos os conjuntos de dados de 1960 e 1970. Os resultados mostram que, baseando-se nas suposições mais razoáveis em vista dos dados deficientes e em deflatores apropriados, a fração da população imersa na pobreza absoluta declina apenas lentamente durante a década.

Apesar de as economias domésticas mais miseráveis serem encontradas entre os pequenos fazendeiros e meeiros das áreas rurais, tanto em 1960 como em 1970, ocorreram grandes aumentos da pobreza nas zonas urbanas, ao longo da década.
O desenvolvimento brasileiro desde 1964 vem sendo assunto controverso há pelo menos uma década, nas discussões sobre estratégias de desenvolvimento econômico. Por um lado, aponta-se o Brasil como exemplo de economia latino-americana bem-sucedida, devido aos seus sete anos de acelerado "milagre econômico" que sucederam a um período de três anos de estabilização econômica, em meados da década de 60. Por outro lado, críticos da política econômica brasileira assinalaram a rápida deterioração da distribuição da renda, que acompanhou esse crescimento miraculoso. Esta mudança ocorrida na distribuição da renda é tão impressionante quanto a das altas taxas de crescimento da renda per capita, já que o montante das distribuiçõés de renda, na maioria dos países em vias de desenvolvimento, tem permanecido notavelmente estável (Dervis et alii, 1982).

Alguns dos críticos dos efeitos da distribuição da renda resultante da política econômica brasileira têm sido ao mesmo tempo críticos da política social e institucional do regime militar que assumiu o poder em 1964 (Hewlitt, 1979).

Cita-se o Brasil, freqüentemente, como exemplo de malogro das políticas de desenvolvimento econômico dos economistas ocidentais e de agências multilaterais de desenvolvimento destinadas a melhorar as condições de vida dos países mais pobres.

0 debate sobre a distribuição da renda no Brasil acirrou-se em várias ocasiôes, em parte devido às diferentes posturas ideológicas dos debatedores, em parte devido à fragilidade dos dados que o embasaram.

A maioria dos estudos baseou-se em publicações de tabulações de pesquisas de amostras por domicílio, que costumeiramente têm sido indicadores imperfeitos da distribuição da renda no Brasil, devido à omissão de dados e subestimações.

Até recentemente, os únicos dados de distribuição da renda com que os pesquisadores podiam contar eram os que diziam respeito à população econômicamente ativa (PEA), os quais encerram a limitação adicional de somente fornecerem dados sobre o fluxo de renda de uma minoria da população.

Baseando-se nessas limitações de dados, alguns proponentes da estratégia econômica brasileira contestavam as bases empíricas das posturas críticas, negando que a magnitude da mudança anteriormente apontada tivesse realmente ocorrido. ${ }^{1}$

Recentemente, o Instituto Brasileiro de Geografia e Estatística (IBGE) liberou para um público restrito de pesquisadores independentes amostras do censo demográfico de 1970.

Os dados ai contidos fornecem grande parte da informação necessária para documentar plenamente a natureza e extensão da desigualdade da renda brasileira e estado de pobreza num quadro empírico aperfeiçoado. Neste estudo, esses dados corrigidos em muitas das deficiências das tabulações publicadas são utilizados para medir o grau de desigualdade de renda e pobreza por domicílios de 1970. Servindo-nos de dados semelhantemente ajustados do censo de 1960 (publicado pela primeira vez por Albert Fishlow em 1972), comparamos a natureza e extensão da pobreza 
no começo e final da década. Chega-se à conclusão de que, ao longo da década, a percentagem de familias em estado de pobreza não diminui consideravelmente no Brasil, mesmo supondo-se uma série de insuficiências no cálculo do nivel de pobreza em 1970. É impossivel fugir à conclusão apontada pelos críticos sobre a compressão da distribuição de renda resultante da política econômica brasileira. Ao analisar as características dos domicílios pobres no começo e final da década, começamos também a delinear neste estudo a história de quais são os grupos sócio-econômicos, no Brasil, que não participaram eqüitativamente do rápido crescimento econômico dos últimos anos da década.

O estudo divide-se da seguinte maneira: no item 2 revê-se o debate sobre a distribuição da renda, fornecendo-se um contexto para os dados apresentados a seguir; no item 3, apresentam-se os resultados empíricos; no item 4, algumas conclusões são oferecidas.

\section{O DEBATE BRASILEIRO}

O debate sobre a distribuição da renda no Brasil teve inicio com a publicação, por Albert Fishlow, em 1972, dos resultados das tabulações dos censos de 1960 e 1970 sobre distribuição da renda. Utilizando dados brutos de uma amostra do censo de 1960 e tabulações publicadas do censo de 1970, Fishlow apresentou resultados que mostravam que, na população economicamente ativa (PEA), a desigualdade de renda medida crescera consideravelmente ao longo da última década. Fishlow apresentou também detalhadas análises dos determinantes da pobreza e desigualdade de renda na amostra de 1960 , servindo-se para tanto da análise de tabelas cruzadas sobre dados familiares e do indice Theil de decomposição para dados de renda.

A explicação inicial de Fishlow para o crescimento da desigualdade na PEA era a política salarial recessiva seguida pelo governo brasileiro durante 0 periodo de estabilização (1963-67). Durante esse período os salários mínimos passaram a ser reajustados muito abaixo do que vinha acontecendo até então, de maneira que, no final desses três anos, os salários mínimos tinham perdido $20 \%$ de seu poder aquisitivo (Fishlow, 1973).

Nos anos seguintes, os salários dos empregados em atividades não-agrícolas sofreram um ligeiro aumento, enquanto as receitas dos empregadores e autônomos cresceram num ritmo muito mais acelerado. Explicações de outros autores centram-se na natureza do crescimento econômico, nos anos que seguiram àqueles da estabilização.

O crescimento do PNB foi de aproximadamente $9 \%$ ao ano entre 1968 e 1971 e esse crescimento concentrou-se nas indústrias modernas de capital intensivo e trabalho altamente qualificado. Esse viés do setor mais moderno no crescimento econômico aumentou a demanda por mão-de-obra especializada, elevando os salários desta em relação aos salários da mão-deobra não-qualificada (Morley e Williamson, 1976).

Relacionado com a hipótese do crescimento do trabalho qualificado está o efeito Kuznets, de crescimento desigual e transferência setorial da distribuição da renda, indicado por Langoni (1973) e defendido pelo governo brasileiro. ${ }^{2}$ Uma explicação recente privilegiou o impacto das mudanças demográficas na estrutura etária da força de trabalho como sendo uma das explicaçōes da crescente desigualdade (Morley, 1981).

De modo geral, nenhuma das explicaçðes sobre o aumento da desigualdade foi realmente convincente, devido às metodologias utilizadas. Para se estabelecer se foram os salários dos trabalhadores de maior renda que foram aumentados, devido à crescente demanda de trabalho especializado que acompanhou o crescimento econômico dos últimos anos da década (posição de Morley e Williamson), ou se foram os salários dos trabalhadores de baixa renda que foram "arrochados" devido à política recessiva (ponto de vista de Bacha, Taylor e Fishlow), o fato é que se tornaram necessárias mais informações do que as que existem no Brasil a respeito de salários em relação à especialização, ocupação e setor econômico, tanto para o setor formal quanto informal - rural e urbano (Macedo, 1977). Há alguma evidência de que ambos os fenômenos ocorreram (Bacha e Taylor, 1978; Morley, 1982). Não obstante, em 1960, 50\% da PEA se compunham de autônomos, de trabalhadores familiares ou meeiros, e $55 \%$ da população viviam em áreas rurais, onde a média dos salários mínimos é muito mais baixa (Meesook, 1972). Por essa razão, qualquer argumento sobre o equilíbrio parcial do padrão salarial urbano, não importa o quão bem seja demonstrado, é necessariamente de valor limitado para explicar a mudança total na desigualdade da distribuição da PEA entre as duas secções cruzadas.

Um modelo de equilíbrio geral, que incorporasse os efeitos de interação dessas políticas sobre o conjunto da força de trabalho, seriam um instrumento mais apropriado para colocar a questão do porquê da deterioração da distribuição de renda. Progressos foram realizados nesse sentido, recentemente, pelo trabalho de Taylor et alii (1980), que utilizou tanto modelo macro de curto prazo quanto modelos de equilíbrio geral computáveis para derivar alguns resultados do impacto da política econômica do governo sobre os retornos do trabalho e do capital durante esse período. Esses autores, baseados em suas simulações, concluem que políticas mais favoráveis aos níveis mais baixos da distribuição da renda - salários mínimos maioires, políticas tributárias de transferência favorecendo as rendas mais baixas, políticas educacionais - poderiam ter produzido uma distribuição de renda mais eqüitativa $e$ altos níveis de crescimento econômico.

Entretanto, pode-se fazer uma outra objeção mais fundamental ao debate tal como ele vem sendo conduzido até agora com base nos tipos de conclusões tiradas da distribuição da PEA até hoje publicadas. A preocupação da maioria dos debatedores tem sido o bem-estar do conjunto da população brasileira. $O$ consenso geral entre os economistas é que a unidade de análise mais adequada para avaliar as mudanças no bem-estar de populações totais é o domićlio. Para a análise dos niveis salariais diferenciais, rendimentos de capital humano e outras categorias de renda semelhantes, a unidade adequada de análise é a renda individual, ou seja, a PEA.

Porém, para a análise do nível de bem-estar econômico da população total, a distribuição da PEA não é 
apropriada. É ao nível da unidade domiciliar que são tomadas as decisões de consumo, e se determina o poder de compra da população total. $O$ bem-estar do assalariado individual é fruto não só do salário que ele/ela ganha no mercado de trabalho, mas do número de pessoas com o qual ele o compartilha. ${ }^{3}$

A distribuição de renda da PEA não mostra essas conexões e com isso não considera o bem-estar dos não assalariados, isto é, a maior parte da população. Embora Fishlow (1972) tenha apresentado dados sobre distribuição de renda por domicílio para 1960 , ele não possuía tais dados para 1970. Todo o debate foi centrado sobre a distribuição da PEA nesses dois períodos. ${ }^{4}$ Para que os resultados das análises da distribuição da PEA pudessem ser interpretados como aplicáveis ao total da população pobre, a categoria das pessoas de baixo rendimento deveria coincidir com a categoria daquelas mesmas pessoas localizadas em seus domicílios. Para o censo de 1970 , Lluch mostrou-nos ser impossível preencher tal condição. Cruzando as tabulações de cada decil de distribuição da PEA por rendimentos, com o decil das suas localizações familiares na distribuição de renda familiar, Lluch concluiu que o decil mais baixo de pessoas na distribuição ultrapassa uniforme e regularmente oito a dez deciles na distribuição de famílias. Segundo Lluch, somente um terço das pessoas recebedoras de renda, classificadas como pobres na distribuição de rendas, localizaram-se em famílias classificadas como pobres de acordo com a distribuição por domicílio. Isto nos fornece uma sólida evidência das limitações da distribuição da PEA como base para a distribuição por domicílios.

Embora análises da distribuição de renda sejam úteis para algumas avaliações sobre a política econômica brasileira, elas não provêem boas informações sobre níveis de bem-estar e pobreza, um tópico que, destacando-se no debate, ainda não merecera uma boa análise a partir dos dados de domicílio. ${ }^{5}$

Uma última deficiência das análises prévias do debate refere-se à qualidade dos dados subjacentes às tabulações publicadas, independentemente da unidade recipiente. Os dados, simplesmente, são falhos.

Em ambos os censos ocorrem subestimaçðes de grande porte. Alguns estimaram que mais de $40 \%$ da renda nacional (medida pelas contas nacionais) de cada um dos anos censitários não foram computados nos resultados dos censos. ${ }^{6}$ Um tipo de renda que está definitivamente excluído da renda medida pelos censos é a renda recebida em espécie, particularmente importante para os autônomos e as áreas rurais. Outro erro de medição surge dos truncamentos da classe de renda mais alta, mais severos em 1960 que em 1970, mas significativos em ambos os anos. Uma terceira questão, que atualmente é um sintoma do problema de unidade recipiente, é o número das pessoas de rendimento zero em ambas as amostras; em 1970 foi de 9,6\% da PEA, em 1960, de 14,7\% (Bacha e Taylor, 1978). Alguns autores que analisaram a distribuição da PEA excluem este grupo, outros qualificam-no como de desempregados. Nenhuma destas abordagens é correta. Eles são empregados e recebem algum tipo de renda - provavelmente em espécie, como as empregadas domésticas, por exemplo, ou são membros da familia que trabalham sem remuneração. $\mathrm{Na}$ sua amostra de 1960, Fishlow corrigiu tais problemas, colocando rendas em espécie no nível mínimo, baseando-se em pesquisas de gastos. Ele não foi capaz de realizar o mesmo para o censo de 1970 e ninguém mais, dos que compararam os censos de 60 e 70, igualmente o fez. ${ }^{7}$ Todo o debate desenvolveu-se em cima destes dados falhos, exigindo traçar-se suposições sobre o nível de renda e bem-estar de 10 a $15 \%$ da população assalariada, cuja renda é, em essência, desconhecida, bem como suposições sobre a distribuição da renda não relacionada.

Notemos, de passagem, que recentemente dois pesquisadores usaram as duas secções cruzadas das distribuições de renda domiciliar para sustentarem suas participações no debate. Fishlow (1980) utilizou-se das distribuições não-ajustadas da renda familiar de cada um dos censos para estimar o número de domicílios na pobreza entre 1960 e 1970. Pfeffermann e Webb (1978) usaram dados de renda familiar publicados, ajustados por "conjecturas", para estimar a mudança na- distribuição de renda familiar ao longo da década. Estes últimos autores concluíram que os dados não-ajustados da distribuição-de renda familiar eram tão pobres que carecia de sentido delinear conclusões definitivas sobre mudanças nas parcelas distributivas. Como observa Lluch $(1982 b)$, o efeito líquido da subestimação indicado por Pfeffermann e Webb quase seguramente suaviza o verdadeiro grau de desigualdade social.

Concordamos, portanto, com Pfeffermann e Webb, embora nossa próxima intervenção no debate seja no sentido de tentar corrigir as deficiências dos dados da amostra não-ajustada.

A utilidade de amostras para uso público do censo de 1970 é que permite aos pesquisadores remediar duas das limitações dos estudos brasileiros anteriores sobre distribuição de renda: os resultados da unidade recipiente $e$ as deficiências de dados. $O$ propósito do trabalho empírico apresentado no item seguinte é o de finalizar tal tarefa. Ajustando as deficiências de dados e compilando tabelas e distribuições do censo de 1970 por unidade domiciliar, podemos estabelecer mais claramente a natureza e o caráter da pobreza e da desigualdade entre os domicílios no Brasil de 1970. Uma vez que estes cálculos foram realizados anteriormente, para o censo de 1960 , por Fishlow (1972) e Meesook (1972), os resultados da amostra de 1970 podem ser comparados com aqueles da década anterior, permitindo que se comece a estabelecer o impacto de década da controversa política econômica sobre os padrões de vida e o bem-estar econômico da população brasileira. Voltemos agora para a apresentação destes resultados.

\section{A COMPARAÇÃO ENTRE 1960 E 1970}

Por volta de 1970 , o milagre brasileiro estava no auge. $\mathrm{O}$ crescimento da produção nesse ano fora superior a $7 \%$ e essa tendência persistiria nos próximos três anos. Embora seja possível argumentar que o real impacto do crescimento, durante o "milagre", não pudesse ser plenamente avaliado quando do censo, a comparação entre o censo de 1960 e 1970 é útil, já que as economias encontravam-se aproximadamente na mesma fase do ciclo econômico, em ambos os períodos. As análises apresentadas a seguir permitem uma visão preliminar so- 
bre o impacto das políticas do período de estabilização e o da primeira metade do período de crescimento. Examinaremos as mudanças ocorridas ao longo da década na distribuição da renda e aquelas ocorridas no nível, características $\mathrm{e}$ intensidade da pobreza absoluta nas unidades familiares do Brasil.

\subsection{Os dados}

As fontes de dados para ambos os períodos são amostras do censo demográfico e a unidade de observação é o domicílio privado. Para o censo de 1970 , os dados são de amostras de 1 para 1.000; no censo de 1960, 1 para 1.400. As tabelas do censo de 1960 foram completadas em 1972 por Albert Fishlow e Oey Astra Meesook (F-M). ${ }^{8}$ A tabulação do censo de 1970 foi realizada pela autora. ${ }^{9}$ Em ambas as tabulações foram feitas aproximações similares dos dados, a fim de corrigir as deficiências já mencionadas: ausência de rendas, truncamento da parcela superior da distribuição e rendas em espécie. Essas correções são detalhadamente descritas por Fox (1982) e Meesook (1972). Os dados de 1960 diferem dos de 1970 em três importantes aspectos:

1. A amostra de 1960 exclui a área de fronteira (7\% da população em 1960).

2. A definição de unidade domiciliar não é a mesma nas duas análises. Em 1960, pensionistas, empregados e agregados estão incluídos como membros da unidade de renda comum, enquanto em 1970 eles estão excluídos. Esse grupo representava, em 1970, 2,6\% da população. ${ }^{10}$

3. Em 1960, a renda foi registrada em intervalos de nove classes, exigindo F-M a fim de usar-se a média da classe de renda, como estimativa da renda por domicílio, na amostra. Em 1970, as cifras de renda do momento foram registradas, permitindo tabulações mais acuradas sobre a distribuição da renda em 1970.

Essas diferenças nos critérios utilizados para a comparação intertemporal sugerem que os resultados apresentados a seguir deveriam ser interpretados com certo cuidado. Felizmente, nos dois casos em que não há coincidência entre as amostras populacionais, os grupos em questão são bastante pequenos. $O$ objetivo dessas comparações através do tempo é poder indicar tendências sugestivas e não evidências absolutas ou números exatos. Embora a insuficiência de dados seja considerável, tais dados sãc seguramente suficientemente comparáveis para servir a nossos propósitos.

\subsection{A distribuição da renda e a incidência da pobreza}

A tabela 1 mostra a distribuição da renda por domicílio em decis populacionais em 1960 e 1970. Esses números confirmam a crença compartilhada pela maioria dos que tomaram parte no debate sobre a distribuição da renda no Brasil, a de que o crescimento da desigualdade da renda deu-se na década de 60 . A participação do decil superior da população na renda cresceu $10 \%$, durante esse período, enquanto que a quota dos quatro decis inferiores diminuiu o mesmo tanto. A renda de todos os outros decis diminuiu, exceção feita aos dois decis superiores, sendo que os maiores ganhos ocorrem no decil mais alto. Isso representa uma mudança considerável para um perfil de renda, ao longo de um período de 10 anos. Não é difícil compreender por que esses números são controvertidos.

As mudanças na distribuição que apresentamos podem ser, grosso modo, comparadas às mudanças ocorridas na distribuição individual citadas por Bacha e Taylor (1978), com uma exceção: a proporção que cabe ao quintil mais pobre sofre uma queda maior na distribuição por domicílio do que na distribuição por renda individual. A mudança ocorrida na distribuição da renda da tabela 1 é um pouco mais dramática que a apresentada por Fishlow (1980), ao utilizar tabulaçōes não-ajustadas para rendas por domicílio.

Tabela 1

A distribuição da renda domiciliar corrigida de 1960 e 1970 (decis de domicílios)

\begin{tabular}{cccccc}
\hline & \multicolumn{2}{c}{1960} & & \multicolumn{2}{c}{1970} \\
\cline { 5 - 6 } \cline { 5 - 6 } Decil & \% de renda & $\begin{array}{c}\text { \% cumulativa } \\
\text { de renda }\end{array}$ & & & $\begin{array}{c}\text { \% de renda } \\
\text { \% cumulativa } \\
\text { de renda }\end{array}$ \\
\hline 10 & 1,4 & 1,4 & & 1,2 & 1,2 \\
10 & 2,4 & 3,8 & & 2,4 & 3,6 \\
10 & 3,6 & 7,4 & & 3,2 & 6,8 \\
10 & 4,6 & 12,0 & & 4,1 & 10,9 \\
10 & 5,6 & 17,6 & & 4,9 & 15,8 \\
10 & 7,2 & 24,8 & & 6,0 & 21,8 \\
10 & 8,1 & 32,9 & & 7,7 & 29,5 \\
10 & 13,1 & 46,0 & & 10,8 & 40,3 \\
10 & 14,6 & 60,6 & 16,6 & 56,9 \\
10 & 39,4 & 100,0 & 43,1 & 100,0 \\
\hline Coeficiente Gini: 0,50 & & & 0,54
\end{tabular}

Fontes: 1960: Fishlow, 1972, tabela 1, distribuição familiar corrigida. Distribuição obtida por interpolação. Cada classe de renda foi suposta como uniformemente distribuida em torno da média. 1970: tabulações do Censo de 1970 da amostra para uso públicc, ajustadas. Distribuição obtida sem interpolação de dados domiciliares individuais.

Servindo-se de dados não-ajustados, Fishlow descobriu que a parcela do decil superior cresceu somente $6 \%$, ou seja, aproximadamente $2 / 3$ do que nós encontramos.

Embora o impacto dos ajustes em ambos os anos visasse igualar a distribuição, parece que o efeito dos ajustes, na amostra de 1960, foi mais igualadora. Uma explicação para isso poderia ser a inexatidão dos dados de 1960 , nos quais a renda era uma variável por categoria.

Mudanças na desigualdade relativa são uma parte da história do impacto da política econômica da década. $O$ que dizer a respeito das mudanças ocorridas nos níveis de pobreza absoluta? Será que o bem-estar dos pobres aumentou apesar da deterioração dos padrões relativos de vida? Para responder a essa pergunta, comparamos a população pobre em ambos os anos, servindo-nos do nível de pobreza definido por Meesook (1972) para a população de 1960 .

O limite de pobreza definido por Meesook para a amostra censitária de 1960 teve por base o salário mínimo do Nordeste naquele ano. Esse montava a aproximadamente $\$ 65$ por mês, em dólares de 70 , corrigindo-se o poder de compra para a família média nordestina. Utilizando-se dos salários mínimos urbanos e rurais do Nor- 
deste separadamente, Meesook corrigiu essa margem para cima, a fim de refletir as diferenças espaciais de preço. Meesook não teve acesso em 1972 aos indices regionais de preços que foram utilizados em outros lugares para esse tipo de análise. ${ }^{11}$ Portanto, ela simplesmente pressupôs, baseada em alguns dados limitados, que as diferenças espaciais nos salários mínimos nordestinos (28\%) refletiam as diferenças existentes entre áreas urbanas e rurais no país e que os preços no Sul e no Leste do país eram $15 \%$ superiores aos do Nordeste. Isso nos leva ao seguinte índice de poder de compra:

\begin{tabular}{lcc}
\hline & Nordeste & Outras regiões $^{12}$ \\
\hline Rural & 1,00 & 1,15 \\
Urbano & 1,28 & 1,47 \\
\hline
\end{tabular}

Fonte: Meesook (1972, p. 123), cálculo nosso.

Enquanto aproximação, esse índice regional de preços não é ruim, julgando-se pelo índice baseado no consumo, encontrado por Williamson (1981). A diferença maior entre os dois índices é a estimativa do Leste e Sul urbanos, que é muito mais alta na aproximação de Meesook do que no índice de Williamson. Isto contribuirá para uma estimativa maior da população em estado de pobreza, nas zonas urbanas em 1970 , do que a que se chegou anteriormente utilizando-se outros índices (Fox, 1982, cap. 3). O limite de pobreza de Meesook foi aplicado a unidades domiciliares estandardizadas quanto ao tamanho e composição.

Para aplicar o limite de pobreza de Meesook à amostra de 1970, o limiar de pobreza de 1960 teve que ser traduzido em NCR $\$$ de 1970 . Isto implica a escolha de um índice nacional de preços para o referidó período. Estimativas da mudança no nível mínimo de preços ao longo do período variavam em mais de $9 \%$ e, como Beckerman e Coes (1980) provaram, a estimativa da população em estado de pobreza em 1970 variará em função do índice de preços escolhido.

Decidimos usar como fator inflacionário o índice do custo de vida de São Paulo (COL), utilizado por Beckerman e Coes como sendo a estimativa mais alta na mudança dos preços nominais ao longo do período. A sensibilidade da nossa estimativa quanto ao tamanho da população pobre, na escolha do deflator, será testada ao aplicar um fator inflacionário de preços mais baixo, ao limite de pobreza F-M de 1960, recalculando a seguir a percentagem da população que vive em estado de pobreza. ${ }^{13}$

Aplica-se o limite de pobreza de Meesook ao conjunto de dados de 1970, a fim de se comparar o número e as características dos domicílios pobres nos dois períodos. Mostramos essa comparação na tabela 2. As duas primeiras linhas mostram que a percentagem de domicílios de pessoas pobres não mudou consideravelmente ao longo do periodo.

Em função da insuficiência de dados para ambos os períodos, não podemos estabelecer com segurança em quanto a incidência da pobreza teria diminuído. Podemos apenas constatar que ela não aumentou e que provavelmente sofreu uma ligeira diminuição. Apesar do rápido crescimento econômico dos últimos anos das décadas, uma minoria da população continuava bastante pobre, qualquer que fossem os padrões utilizados.

A maré de crescimento parece ter deixado para trás cerca de $30 \%$ da população de 1970 .

Embora em termos absolutos a pobreza pouco tenha-se modificado, a forma por ela assumida em 1970 diferencia-se daquela assumida em 1960 sob muitos aspectos, como poderemos ver no resto da tabela. A comparação dos números da terceira e sexta colunas mostra como a incidência relativa da pobreza mudou ao longo da década no que diz respeito às diferentes características da população. Quando o número é igual a 1 , a incidência das características da categoria é a mesma que as características da população. Caso o número seja superior a 1 , um número desproporcional de pessoas pobres tem essas características. A maneira pela qual esses números mudam ao longo do tempo nos dá indicações sobre como a população pobre está mudando em relação à população como um todo. A principal modificação ocorrida na população ao longo da década foi o grande aumento da pobreza urbana. Em 1960, 64,3\% dos domicílios pobres situavam-se en áreas rurais, mas, já em 1970, os domicílios pobres estavam divididos igualmente entre as zonas urbanas e rurais.

A incidência relativa da pobreza nas zonas rurais em 1960 era de 1,26; em 1970 caiu para 1,18. Isso sugere que, ao longo da década, a pobreza passou a distribuir-se igualmente entre as regiōes urbanas e rurais. ${ }^{14} \mathrm{~A}$ década caracterizou-se por grande fluxo migratório rural-urbano (Morley, 1982, cap. 6) e tudo indica que a pobreza acompanhou os emigrantes em sua vinda para a cidade e que essa migração poderia igualmente ter comprimido os salários urbanos. Em 1970, a incidência relativa da pobreza entre os não-migrantes foi inferior a 1, uma modificação em relação ao período anterior que sugere que parte dos migrantes pioraram ou não melhoraram de vida com a imigração. ${ }^{15}$

Regionalmente, a pobreza mantém-se concentrada no Nordeste. Em 1970, a incidência relativa da pobreza foi inferior a 1 , tanto no Leste quanto no Sul, indicando que essas regiões continuavam a se beneficiar da concentração do desenvolvimento econômico nessas regiões.

Quando analisamos a incidência de pobreza segundo a localização urbano/rural e regional, descobrimos que, em 1970 , a incidência da pobreza no Nordeste rural é duas vezes maior do que a do país como um todo e que os domicílios localizados no Nordeste rural têm $41 / 3$ mais chances de se encontrarem em estado de pobreza que os domicílios localizados no Sudeste urbano. ${ }^{16}$

Domicílios onde o chefe de família é uma mulher continuam a ter chances muito maiores de serem pobres em 1970, assim como os de não-trabalhadores. Os pobres, em sua maior parte, continuam sendo trabalhadores pobres e não um grupo de desempregados ou incapazes. As famílias pobres continuam sendo mais numerosas e os chefes de família ligeiramente mais jovens, embora essa diferença possa ser simplesmente um reflexo da menor duração da vida entre os pobres e não um efeito da renda no ciclo vital. Chefes de familia que constituem a principal fonte de renda do domicílio são de modo geral mais escolarizados em 1970 (Fox, 1982, 
cap. 3) que em 1960. Apesar de mais da metade dos chefes de domicílios pobres em 1970 afirmar não ter nenhuma escolaridade, $a$ incidencia relativa de chefes de família pobres com alguma educação cresceu ao longo da década. Embora a educação tenha reduzido drasticamente a probabilidade de ser pobre em 1970, ela não garantiu tampouco uma boa renda.

Com a crescente incidência de pobreza em meio à população urbana, no final da década, a distribuição do setor de atividade dos chefes de família em estado de pobreza também mudou. Embora a proporção de chefes de domicílios pobres empregados em atividades agrícolas tenha-se reduzido de $20 \%$, ao longo da década, a incidência relativa sofreu um ligeiro aumento, devido à diminuição da população empregada na agricultura durante esta década. A ocupação urbana que abrangia mais domicílios pobres era a comercial - vendedores, incluindo ambulantes - ou seja, um importante setor de atividade informal. Ao mesmo tempo, diminuiu a incidência relativa de pobreza no setor de serviços, outra importante atividade informal urbana. $\mathbf{A}$ indústria, portanto, entendida como uma atividade primária dos domicílios pobres, sugere que pode haver algo de verdadeiro na hipótese de Fishlow (1972) e outros, de que a queda dos salários mínimos atingiu os pobres às custas dos ricos. Outra sugestiva evidência para tal afirmação é o aumento da pobreza relativa nos domicílios em que o chefe é empregado do setor privado. Note-se, porém, que as categorias "indústria" e "setor privado" incluem também parte do assim chamado setor informal, como por exemplo o artesanato caseiro.

Apesar de o tamanho da família e o número de filhos ter-se mantido basicamente igual ao longo da década, o número de trabalhadores adicionais por família,

Tabela 2

Características dos domicílios pobres e não-pobres em 1960 e 1970

(Percentagem de domicílios)

\begin{tabular}{|c|c|c|c|c|c|c|}
\hline & $\begin{array}{l}\text { Domicílios } \\
\text { pobres }\end{array}$ & $\begin{array}{l}\text { Domicílios } \\
\text { não-pobres }\end{array}$ & $\begin{array}{l}\text { Incidência } \\
\text { relativa de } \\
\text { pobreza }{ }^{a}\end{array}$ & $\begin{array}{c}\text { Domicílios } \\
\text { pobres }\end{array}$ & $\begin{array}{l}\text { Domicílios } \\
\text { não-pobres }\end{array}$ & $\begin{array}{l}\text { Incidência } \\
\text { relativa de } \\
\text { pobreza }^{a}\end{array}$ \\
\hline $\begin{array}{l}\text { Percentagem de domicilios } \\
\text { Percentagem da populaçāo } \\
\text { Tamanho familiar médio }\end{array}$ & $\begin{array}{l}27 \\
34 \\
6,1\end{array}$ & $\begin{array}{l}73 \\
66 \\
4,5\end{array}$ & & $\begin{array}{r}23,7 \\
30,5 \\
6,4\end{array}$ & $\begin{array}{r}76,3 \\
69,5 \\
4,6\end{array}$ & \\
\hline $\begin{array}{l}\text { Região: } \\
\text { Nordeste } \\
\text { Leste } \\
\text { Sul } \\
\\
\text { Fronteiriça }\end{array}$ & $\begin{array}{l}40,8 \\
41,1 \\
18,2\end{array}$ & $\begin{array}{l}17,1 \\
37,8 \\
45,1\end{array}$ & $\begin{array}{l}1,73 \\
1,06 \\
0,48\end{array}$ & $\begin{array}{r}48,1 \\
21,4 \\
20,9 \\
9,6\end{array}$ & $\begin{array}{r}23,1 \\
24,8 \\
43,2 \\
8,9\end{array}$ & $\begin{array}{l}1,65 \\
0,89 \\
0,54 \\
1,05\end{array}$ \\
\hline $\begin{array}{l}\text { Localização: urbana e suburbana } \\
\text { rural }\end{array}$ & $\begin{array}{l}35,7 \\
64,3\end{array}$ & $\begin{array}{l}54,3 \\
45,7\end{array}$ & $\begin{array}{l}0,78 \\
1,26\end{array}$ & $\begin{array}{l}49,4 \\
50,6\end{array}$ & $\begin{array}{l}61,2 \\
38,8\end{array}$ & $\begin{array}{l}0,85 \\
1,18\end{array}$ \\
\hline $\begin{array}{l}\text { Atividade econômica do chefe: } \\
\text { Trabalhando ou procurando trabalho } \\
\text { Não trabalhando }\end{array}$ & $\begin{array}{l}82,2 \\
17,8\end{array}$ & $\begin{array}{r}91,6 \\
8,4\end{array}$ & $\begin{array}{l}0,92 \\
1,62\end{array}$ & $\begin{array}{l}79,7 \\
20,3\end{array}$ & $\begin{array}{l}87,0 \\
13,0\end{array}$ & $\begin{array}{l}0,93 \\
1,37\end{array}$ \\
\hline $\begin{array}{l}\text { Sexo do chefe: } \\
\text { Masculino } \\
\text { Feminino }\end{array}$ & $\begin{array}{l}82,9 \\
17,1\end{array}$ & $\begin{array}{r}91,5 \\
8,5\end{array}$ & $\begin{array}{l}0,93 \\
1,57\end{array}$ & $\begin{array}{l}82,0 \\
18,0\end{array}$ & $\begin{array}{l}89,4 \\
10,6\end{array}$ & $\begin{array}{l}0,94 \\
1,45\end{array}$ \\
\hline $\begin{array}{l}\text { Idade do chefe: menos de } 30 \\
30-39 \\
40-49 \\
50-59 \\
60+\end{array}$ & $\begin{array}{l}14,0 \\
28,2 \\
27,4 \\
15,4 \\
14,4\end{array}$ & $\begin{array}{l}21,3 \\
28,2 \\
21,4 \\
15,6 \\
13,5\end{array}$ & $\begin{array}{l}0,73 \\
1,01 \\
1,19 \\
0,99 \\
1,04\end{array}$ & $\begin{array}{l}12,2 \\
29,6 \\
22,7 \\
16,8 \\
13,6\end{array}$ & $\begin{array}{l}19,8 \\
26,0 \\
22,7 \\
17,0 \\
14,5\end{array}$ & $\begin{array}{l}0,67 \\
1,10 \\
1,16 \\
0,99 \\
0,95\end{array}$ \\
\hline $\begin{array}{l}\text { Educação do chefe: } \\
\text { Nenhuma } \\
\text { Alguma primária } \\
\text { Alguma secundária inferior } \\
\text { Alguma secundária superior } \\
\text { Alguma universitária }\end{array}$ & $\begin{array}{r}65,0 \\
34,2 \\
0,6 \\
0,1 \\
0,1\end{array}$ & $\begin{array}{r}36,0 \\
54,3 \\
5,2 \\
2,3 \\
2,1\end{array}$ & $\begin{array}{l}1,48 \\
0,70 \\
0,16 \\
0,06 \\
0,05\end{array}$ & $\begin{array}{r}67,8 \\
33,4 \\
3,3 \\
0,5 \\
0,1\end{array}$ & $\begin{array}{r}34,1 \\
43,9 \\
11,0 \\
7,7 \\
3,3\end{array}$ & $\begin{array}{l}1,53 \\
0,81 \\
0,35 \\
0,08 \\
0,02\end{array}$ \\
\hline $\begin{array}{l}\text { Status migratório do chefe: } \\
\text { Migrante da área rural } \\
\text { Migrante da área urbana } \\
\text { Não-migrante }\end{array}$ & $\begin{array}{l}13,4 \\
19,2 \\
67,4\end{array}$ & $\begin{array}{l}14,6 \\
35,9 \\
49,5\end{array}$ & $\begin{array}{l}0,94 \\
0,61 \\
1,24\end{array}$ & $\begin{array}{r}6,0 \\
66,4 \\
27,6\end{array}$ & $\begin{array}{r}5,5 \\
55,6 \\
38,9\end{array}$ & $\begin{array}{l}1,14 \\
1.06 \\
0,76\end{array}$ \\
\hline $\begin{array}{l}\text { Setor de emprego do chefe: } \\
\text { Agricul tura e extração } \\
\text { Indústria } \\
\text { Serviços } \\
\text { Comércio } \\
\text { Transporte e comunicações } \\
\text { Estado, prof. liberais, outras }\end{array}$ & $\begin{array}{r}72,9 \\
8,4 \\
8,3 \\
4,3 \\
4,2 \\
2,0\end{array}$ & $\begin{array}{r}48,7 \\
15,7 \\
8,4 \\
11,4 \\
7,9 \\
7,9\end{array}$ & $\begin{array}{l}1,22 \\
0,56 \\
0,91 \\
0,41 \\
0,55 \\
0,29\end{array}$ & $\begin{array}{r}66,4 \\
14,4 \\
5,5 \\
6,5 \\
3,1 \\
4,1\end{array}$ & $\begin{array}{r}41,6 \\
21,4 \\
11,5 \\
6,1 \\
6,8 \\
12,6\end{array}$ & $\begin{array}{l}1,38 \\
0,70 \\
0,52 \\
1,03 \\
0,51 \\
0,37\end{array}$ \\
\hline
\end{tabular}




\begin{tabular}{|c|c|c|c|c|c|c|}
\hline & $\begin{array}{l}\text { Domicílios } \\
\text { pobres }\end{array}$ & $\begin{array}{l}\text { Domicílios } \\
\text { não-pobres }\end{array}$ & $\begin{array}{c}\text { Incidência } \\
\text { relativa de } \\
\text { pobreza }\end{array}$ & $\begin{array}{l}\text { Domicílios } \\
\text { pobres }\end{array}$ & $\begin{array}{l}\text { Domicílios } \\
\text { não-pobres }\end{array}$ & $\begin{array}{c}\text { Incidência } \\
\text { relativa de } \\
\text { pobreza }\end{array}$ \\
\hline \multicolumn{7}{|l|}{ Posição e ocupação do chefe: } \\
\hline Empregado do setor público & 2,4 & 9,2 & 0,30 & 4,8 & 11,3 & 0,45 \\
\hline Empregado do setor privado & 35,9 & 38,5 & 0,88 & 35,9 & 40,8 & 0,84 \\
\hline Autônomo & 52,4 & 44,6 & 1,04 & 45,2 & 38,9 & 1,05 \\
\hline Meeiro ou trabalhador familiar & 8,6 & 3,6 & 1,66 & 13,6 & 5,6 & 1,72 \\
\hline Empregador & 0,6 & 4,1 & 0,17 & 0,5 & 3,4 & 0,18 \\
\hline \multicolumn{7}{|c|}{ Número dos economicamente ativos } \\
\hline 0 & 11,4 & 3,0 & 2,16 & 13,7 & 5,1 & 1,92 \\
\hline 1 & 54,9 & 62,2 & 0,91 & 56,9 & 58,4 & 0,98 \\
\hline 2 & 16,5 & 20,6 & 0,85 & 15,8 & 21,7 & 0,78 \\
\hline 3 ou mais & 17,2 & 14,3 & 1,14 & 3,2 & 14,8 & 0,94 \\
\hline \multicolumn{7}{|c|}{ Número de crianfas menores de 14 anos } \\
\hline 0 & 15,0 & 33,4 & 0,53 & 19,8 & 37,2 & 0,59 \\
\hline $1-i$ & 28,7 & 37,7 & 0,81 & 19,5 & 36,0 & 0,61 \\
\hline $3-4$ & 26,5 & 19,6 & 1,23 & 27,7 & 18,6 & 1,34 \\
\hline 5 ou mais & 29,7 & 9,4 & 1,99 & 33,0 & 8,3 & 2,33 \\
\hline \multicolumn{7}{|l|}{$\begin{array}{l}\text { Número de crianças menores } \\
\text { de } 14 \text { anos na escola }\end{array}$} \\
\hline 0 & 65,6 & 67,3 & 0,98 & 43,8 & 47,1 & 1,13 \\
\hline $1-2$ & 23,0 & 25,4 & 0,93 & 34,9 & 39,5 & 1,09 \\
\hline 3 ou mais & 11,4 & 7,3 & 1,36 & 21,3 & 13,4 & 1,63 \\
\hline
\end{tabular}

Fontes: 1960: Meesook (1972); 1970; ver texto. Utiliza-se a estimativa da margem superior do limite de pobreza para 1970.

$a$ Incidência de pobres na categoria como um múltiplo da incidência geral de pobreza $(26,6 \%)$.

$b$ A amostra de Fishlow, de 1970, exclui a área de fronteira.

entre os pobres, diminuiu levemente. Ao mesmo tempo, aumentou o número de crianças pobres escolarizadas. Esse é o único ponto luminoso no quadro sombrio que traçamos sobre os efeitos da política econômica, ao longo da década. Parece - talvez um efeito da crescente urbanização - que um número crescente de crianças pobres está nas escolas, ao invés de estar no trabalho.

Enquanto o número de domicílios pobres parece ter diminuído apenas ligeiramente, a renda média desses pode ter aumentado, o que significaria uma redução na intensidade da pobreza, não calculada na referida tabela. Infelizmente, os dados de 1960 não permitem o cálculo de uma "diferença de pobreza" ou alguma outra medida do gênero. A única medida de intensidade de po-

Tabela 3

Distribuição das Rendas por domiício na escala de pobreza - domicílios abaixo do limite de pobreza

\begin{tabular}{|c|c|c|c|}
\hline Múltiplo da Renda de pobreza & 1960 & 1970 & $1970-60$ \\
\hline $\begin{array}{l}0 \\
0.01-0,25 \\
0,26-0,50 \\
0,51-0,75 \\
0,76-1,00\end{array}$ & $\begin{array}{r}1,8 \\
0,8 \\
5,3 \\
8,7 \\
10,6 \\
\end{array}$ & $\begin{array}{l}0,4 \\
1,3 \\
4,7 \\
7,6 \\
9,9 \\
\end{array}$ & $\begin{array}{l}0,22 \\
1,62 \\
0,89 \\
0,87 \\
0,93 \\
\end{array}$ \\
\hline Total & $\overline{27.2}$ & $\overline{23,9}$ & $\overline{4,53}$ \\
\hline $\begin{array}{l}\text { Renda principal } \\
\text { (múltiplo do limite de pobreza) }\end{array}$ & 0,627 & 0,634 & 1,01 \\
\hline
\end{tabular}

Fontes: 1960 - Meesook (1972, p. 136); 1970 - Estimativa nossa. Utiliza-se a estimativa superior para o limite de pobreza para 1970. breza possivel de ser calculada a partir dos dois conjuntos de dados existentes é o que apresentamos na tabela 3 , a distribuição das rendas familiares na escala de pobreza para as séries de tempo.

Multiplicando-se o percentual de domicílios pobres pelo ponto médio do intervalo, é possivel calcular-se à renda média da pobreza. Embora o quadro mostre uma acentuada redução do número de domicílios de renda zero, $^{17}$ a renda média dos domić́lios pobres não mudou ao longo da década. Esses domicílios que não saíram do estado de pobreza, ao fim da década, não parecern ter conseguido diminuir a intensidade de suas privações.

\subsection{Análise de sensibilidade}

Até que ponto os resultados das tabelas 2 e 3 são sensíveis às suposições que fizemos ao construir o limite de pobreza para 1970? Para responder a esta questão, uma análise de sensibilidade foi realizada a partir do número e distribuição local da população pobre em relação a duas das suposições-chave feitas aqui: a) o inflator de preços; b) a estimativa de salário em espécie. Os resultados são mostrados na tabela 4. Para as duas primeiras estimativas (linhas 2-3) utilizaram-se os dados de renda em espécie que F-M usaram em seu trabalho com a amostra de 1960, dados das pesquisas orçamentárias realizadas pela Fundação Getulio Vargas (FGV) em 1962-63 (Meesook, 1972 , p. 127). Vemos que nossas estimativas sobre o tamanho da população em estado de pobreza são de fato sensiveis ao inflator escolhido. Uma redução de $8 \%$ no limite de pobreza resulta em uma redução de $15 \%$ no tamanho da população pobre. A distribuição rural- 
urbana da população pobre altera-se apenas ligeiramente, indicando, contudo, a força desse resultado. A alta elasticidade da proporção da população em estado de pobreza em relação à mudança no limite de pobreza é um resultado observado em outra pesquisa com este conjunto de dados (Fox, 1982). A conclusão que poderíamos traçar a partir desta análise de sensibilidade é a de que, no máximo, a percentagem da população na pobreza decaiu levemente durante a década, porém devido à fragilidade das cifras de renda de 1960, quase mais nada se pode dizer a respeito.

Desde que F-M completaram sua análise, em 1970, uma pesquisa de consumo nacional (Endef) foi realizada,

Tabela 4

Tamanho e localização da população pobre sob diferentes suposições

\begin{tabular}{llcc}
\hline 1) Estimativa de Meesook & & Pobres & Não-pobres \\
para 1960 & & \\
Percentagem de domicílios & 27 & 73 \\
$\begin{array}{l}\text { Percentagem da população } \\
\text { Distribuição locacional do }\end{array}$ & 34 & 66 \\
grupo (\%): & Urbano & 35,7 & 54,3 \\
& Rural & 64,3 & 45,7
\end{tabular}

2) Nossa estimativa para 1970 , dados FGV, limite de pobreza superior

Percentagem de domicílios Percentagem da população Distribuiçâo locacional do grupo (\%) :

$\begin{array}{lll} & 23,7 & 76,3 \\ & 30,5 & 69,5 \\ & & \\ \text { Urbano } & 49,4 & 61,2 \\ \text { Rural } & 50,6 & 38,8\end{array}$

3) Nossa estimativa para 1970 , dados FGV, limite de pobreza inferior

Percentagem de domicílios Percentagem da população Distribuição locacional do grupo (\%):

$\begin{array}{lll} & 20,6 & 79,6 \\ & 26,5 & 73,5 \\ & & \\ \text { Urbano } & 48,8 & 60,9 \\ \text { Rural } & 51,2 & 39,1\end{array}$

4) Nossa estimativa, dados Endef, limite de pobreza superior

Percentagem de domicílios Percentagem da população Distribuição locacional do grupo (\%)

$\begin{array}{lll} & 24,3 & 75,7 \\ & 31,7 & 68,3 \\ & & \\ \text { Urbano } & 41,3 & 63,9 \\ \text { Rural } & 58,7 & 36,1\end{array}$

5) Nossa estimativa, dados Endef, limite de pobreza inferior

Percentagem de domicílios Percentagem da população Distribuição locacional do grupo (\%):

\begin{tabular}{lll} 
& 20,9 & 79,1 \\
& 27,4 & 72,6 \\
& & \\
Urbano & 41,3 & 62,9 \\
Rural & 58,7 & 37,1 \\
\hline
\end{tabular}

Limite de pobreza superior para 1970: NCR $\$ 140$ rural, NCR $\$ 175$ urbano. Indice de preço $=38,26$

Limite de pobreza inferior para 1970: NCR $\$ 129$ rural, NCR \$161 urbano, Indice-te preço $=35,32$

Limite de pobreza para 1960: NCR \$ 3,66 rural, NCR\$ 4,57 urbano. permitindo melhores estimativas sobre o montante da renda em espécie. A autora solicitou tabulações especiais desta pesquisa, para uma investigação anterior sobre a distribuição da renda (Fox, 1982), e estas tabulações contêm estimativas de renda em espécie para as áreas rural e urbana. Isto explicaria o fato de termos encontrado uma ampla fração de domícilos pobres nas áreas urbanas? Em outras palavras, o uso do método F-M atenuaria a ręnda urbana a ponto de levar tais domicrílios à pobreza? Nossa segunda análise de sensibilidade sugere que este pode ter sido o caso. Substituindo dados de renda ajustada Endef, da nossa análise anterior, pelos dados da FGV até agora utilizados nesta análise, calculamos a proporção de domicílios na pobreza e a distribuição local dos domicílios pobres e não-pobres (linhas 4-5). Comparando a linha 2 com a linha 4 (ou linha 3 com linha 5), torna-se claro que embora a percentagem de pobreza não se altere muito usando-se os dados Endef da renda em espécie, a distribuição rural/urbana, pelo contrário, se modifica. ${ }^{18}$ Essa análise de sensibilidade sugere que há um grande número de domićlios nas áreas rurais e urbanas no limiar da pobreza, que sobrevivem de alguma forma.

Poder-se-ia pensar que o efeito do uso de ajustamentos de renda em espécie F-M poderia suavizar a pobreza urbana nos dois períodos, uma vez que para nossos cálculos de 1970 nós simplesmente aplicamos suas estimativas usadas na leitura das tabulaçōes de 1960. Portanto, nossa conclusão relativa à direção da aiteração seria sólida. Infelizmente isto não é verdade, porque mudanças institucionais importantes ocorreram, entre 1960 e 1970 , na forma de remuneração do setor formal urbano. Em 1963, sancionaram-se duas leis que estabeleciam pagamentos de benefícios adicionais para os trabalhadores do setor moderno: um benefício familiar, estabelecendo $5 \%$ do salário mínimo para cada criança do domicílic do trabalhador menor de 15 anos e um bônus salarial de 13ㅇ mês a ser pago em dezembro (Gregory, 1974). O efeito destas duas leis foi aumentar os benefícios adicionais, numa média de $15 \%$ da renda monetária. Gregory estimou que a incidência desses benefícios adicionais recaiu quase inteiramente sobre os trabalhadores, implicando que os salários mensais, em dinheiro, como fração da renda total da família, declinassem durante o período. Idealmente, a renda registrada pelo censo deveria incluir estes dois itens (assim como benefícios adicionais não-monetários), mas é muito provável que o 13 올 salário não esteja incluído, uma vez que o censo pede a renda média mensal.

Nossa conclusão, por conseguinte, é de que houve algum aumento na pobreza urbana, durante a década. Se este aumento foi mais rápido, mais lento ou igual ao aumento geral de urbanização ao longo da década, é impossível saber devido às limitações dos nossos dados. A proporção exata dos domicílios pobres nas áreas urbanas é impossivel de ser medida acuradamente, mas, de acordo com todas as nossas suposições, é substancial.

\section{CONCLUSÕES}

Neste estudo, a distribuição de renda e a pobreza brasileira foram abordadas dentro de uma perspectiva histórica, utilizando-se de dados sobre a distribuição de renda e 
pobreza nas unidades familiares. Trata-se da primeira vez em que se realiza tal tipo de análise, usando-se dados ajustados e corrigidos para ambos os períodos de tempo. Embora os resultados aqui apresentados não destoem das expectativas da maioria dos participantes e observadores do debate sobre a distribuição de renda no Brasil, algumas surpresas ocorreram. A maior delas foi o crescimento da pobreza urbana durante a década.

A distribuição domiciliar ajustada, apresentada neste trabalho, confirma o que a maioria dos especialistas suspeitava: a parcela inferior do espectro da renda familiar perdeu terreno, em termos relativos, durante a década. As alterações proporcionais foram dramáticas, para um período de tempo tão curto como este. Cálculos recentes, que utilizam as tabulações preliminares dos dados do censo de 1980 (população economicamente ativa) indicam que, nesta última década, ainda não ocorreu a reversão daquela tendência (Denslow e Tyler, 1983). A estimação dos trabalhos sobre a renda familiar a partir do exemplar acessivel ao público do censo de 1980 fornecerá evidências mais definitivas sobre a questão.

Apenas os próprios brasileiros serão capazes de avaliar os custos relativos e benefícios da estratégia de desenvolvimento econômico do governo militar. É evidente que a exclusão de segmentos da população do milagre brasileiro constituiu-se em uma das mais fortes pressões no sentido da liberalização política, nos anos recentes. Infelizmente, os custos de uma política voltada para as necessidades destas camadas são crescentes e não decrescentes ao longo do tempo, devido às restrições externas extremamente sérias que a economia brasileira enfrenta hoje. A estratégia governamental - primeiro crescer, depois redistribuir - poderá reduzir-se a uma estratégia unicamente de crescimento. Este será efetivamente um resultado trágico e provavelmente evitável. ${ }^{19}$

É possível crescer a partir de uma dada desigualdade e, ao mesmo tempo, graças a um efeito de transferência setorial, aumentar em termos absolutos as rendas inferiores. Embora alguma transferência de rendas deva haver ocorrido durante a década (como a urbanização crescente e a saída da população da agricultura indicam), as estimativas apresentadas mostram como a proporção dos domicílios pobres não se alterou substancialmente durante a década. Isto sugere que as explicações sobre o aumento da desigualdade relativa (e as justificativas ex post a respeito) deveriam ir além de simples efeitos Kuznets e considerar a estrutura da política econômica e o desenvolvimento econômico ao longo da década. Os efeitos iniciais das políticas econômicas da década parecem não haver elevado acima do limite de pobreza a renda absoluta da fração da população considerada pobre de acordo aos padrões de 1960 , mas simplesmente alterado a incidência de pobreza nas áreas urbanas.

O perfil de pobreza apresentado não inclui informações sobre o acesso a serviços públicos durante a década. Excetuando-se a observação de algum crescimento no número de matrículas de crianças pobres, não podemos oferecer qualquer tipo de conclusões a respeito de mudanças em indicadores de bem-estar social desvinculados de rendas. Nossa expectativa a priori seria a de uma me- lhora do bem-estar para aquelas famílias que classificamos de pobres, graças à urbanização crescente. ${ }^{20}$ Porém, esta limitação dos nossos dados deveria ser recordada quando avaliamos o bem-estar dos segmentos mais pobres durante os dois periodos de tempo.

\begin{abstract}
* Tradução de Caterina Koltay. Este traballıo baseia-se na pesquisa de dissertação da autora. que a completou enquanto pertencia ao staff do World Bank. Ela agradece a Samuel A. Morley, por seus extensos comentários realizados a partir de uma versão mais longa deste trabalho, que apareceu como o capítulo 5 de sua dissertação. As conclusões e pontos de vista expressos neste trabalho são da autora e não necessariamente refletem aqueles do grupo do World Bank.
\end{abstract}

1 Pfeffermann e Wcbb (1978) sustentaram esta opinião. Ver Bacha e Taylor (1978), para a discussão das mudanças nesta posição e uma apreciação crítica.

2 Bacha e Taylor (1978) realizaram um excelente exame do debate, tal qual ele se encontrava em 1977 e não seria necessário repeti-lo agora. Em seus artigos usaram uma abordagem de análise de variância para rejcitar o efeito Kuznets como a mclhor explicação of erecida para o aumento da dispersão de 1970 .

${ }^{3}$ Embora Kuznets (1955) tenha explicitamente ressaltado este ponto, até recentemente muitos especialistas em distribuição dc renda o ignoraram. Ver, por exemplo, Chencry et alii (1974, cap. 1).

4 Exceções recentes foram as análises de Fishlow (1980) e de Pfeffermann e Webb (1978, parte 1). Estas duas análises, contudo, baseiam-se em dados imperfeitos, como se discutirá mais adiante.

5 Fishlow (1980) considera este aspecto na sua crítica à análise de Fields (1977). Fields tentou medir mudanças na incidência de pobreza utilizando-se de duas distribuições de PEA.

6 Lluch considerou tal questão. Após corrigir o mais razoavelmente possível suas medidas ajustadas de renda nacional cm virtude da subestimação ocorrida na amostra de 1960, Meesook (1972) conciliou-as com as contas nacionais. É importante observar que as contas nacionais são igualmente objeto de erros. Para extrair-se uma medida da renda pessoal total na economia a partir das contas nacionais, importantes suposiçōes precisaram ser feitas. Devido à subjetividade destas suposições, nós não acreditamos que estimativas da renda pessoal total para as contas nacionais representem os únicos padrões a partir dos quais se possa julgar estimativas de renda do censo.

7 Langoni (1975) realizou ajustes para rendas em espécie, nas suas tabulações de dados da PEA retirados do censo de 1970. Entretanto, para os propósitos de sua comparação entre 1960 e 1970 , ele usou dados não-ajustados. Uma vez que seu método de ajuste para renda em espécie na amostra de 1970 e o de FishlowMeesook para a amostra de 1960 são distintos, a comparação entre ambos torna-se difícil. Pfeffermann e Webb dão estimativas da redução da desigualdade que poderia ocorrer se à renda em espécie fosse acrescentada a renda medida, mas esses núme- 
ros devem ser considerados, no máximo, como conjecturas bem feitas.

8 Resultados desta tabulação foram publicados em dois lugares: no artigo de Fishlow (1972) e na tese de Ph.D de Meesook (1972). A apresentação diferiu um pouco nos dois trabalhos, mas a base dos dados subjacentes era a mesma amostra ajustada do censo de 1960 . Utilizamos a tabela de Fishlow para a distribuição de renda na nossa comparação de desigualdade relativa e a tabela das características dos pobres para as nossas tabulações do nível de pobreza, uma vez que Meesook fornece uma discussão muito mais clara sobre sua metodologia do que Fishlow. Referimo-nos a esta metodologia conjunta como o método Fishlow-Meesook (F-M).

9 Resultados desta tabulação, assim como a extensa documentação sobre a metodologia usada na análise descrita aparece em Fox (1982).

10 Ver Fox (1982, cap. 2), para uma discussão completa sobre as questões que ocasionaram esta diferença em metodologia.

11 Ver Fox (1982), para outro cálculo do nível de pobreza usando índices de preços derivados de uma pesquisa de consumo de 1974, Endef.

12 F-M não incluem a área de fronteira em suas tabulações de 1960. Para podermos aplicar o índice à nossa amostra de 1970 , partimos do pressuposto de que a área de fronteira tinha a mesma relação de custo espacial em relação ao Nordeste do que em relação ao resto do Brasil.

13 Para nós, o indice ideal de preços seria aquele que refletisse as variaçōes de preço da cesta básica a ser consumida pelos pobres. Esse indice não existe. Contudo, estimativas calculadas a partir do COL da Guanabara, composto de sete indices distintos, e a cesta básica (calculada por dados Endef) que representasse a distribuição das aquisições de bens e serviços pelo quintil mais pobre, sugerem que o uso do COL de São Paulo subestima ligeiramente a maneira pela qual as transformações do índice nacional de preços afetou o segmento mais pobre da população.

14 Utilizando um limite de pobreza mais baixo (Fox, 1982, cap. 3), encontrei uma incidência relativa muito mais elevada de pobreza nas áreas rurais. Como foi dito, o método $F-M$ de retificar os dados e traçar um limite de pobreza apresenta um viés urbano e, conseqüentemente, encontramos uma incidência relativa da pobreza mais baixa na zona rural do que usando outros métodos.

15 Essa observação não leva em conta o maior acesso a serviços públicos de todos os grupos de renda que se dá com a crescente urbanização. Se puderem escolher, talvez muitos migrantes prefiram ser pobres na cidade do que no campo, mas nossos dados não permitem medir esse item. Para evidência sobre serviços, ver Knight e Moran (1979 a).

${ }^{16}$ Fox (1982, p. 74) apresenta esses cálculos. Infelizmente, essá mesma classificação em seis classes de domicílios por região não existe para os dados de 1960 .

17 Esse decréscimo na proporção de trabalhadores de renda zero pode representar simplesmente uma melhor adequação do instrumental do censo de 1970 , já que o censo de 1960 incluía somente nove classes de renda. E necessário ressaltar que os números que aparecem no quadro 3 para 1960 são estimados muito aproximadamente.

18 As estimativas de gastos em espécie do Endef são ligeiramente superiores, em média, do que as estimativas da FGV.

19 Ver Knight (1981), para uma visão mais exata das perspectivas de políticas de desenvolvimento equiitativo para os anos $\mathbf{8 0}$.

20 Knight e Moran (1979 a) apresentam dados que sugerem que isso poderia ser verdadeiro.

\section{REFERENCIAS BIBLIOGRÁFICAS}

Bacha, Edmar \& Taylor, Lance. Brazilian income distribution in the 1960's: facts, Model results and the controversy. Joumal of Development Studies, 14 (3), Apr. 1978.

Beckerman, Paul \& Donald, Coes. Who benefits from economic development? : comment. American Economic Review, 70 (1), Mar. 1980.

Chenery, Hollis; Ahluwalia, Montek S., Bell, C. L. G., Duloy; John H. \& Jolly, Richard. Redistribution with growth, New York, Oxford University Press, 1974.

Denslow, David Jr. \& Tyler, William. Perspectives on Poverty and income inequality in Brasil. 1983, mimeogr.

Dervis, Kemal; Melo, Jaime de \& Robinson, Sherman. General equilibrium models for development policy. Cambridge, Cambridge University Press, 1982.

Fishlow, Albert. Brazilian size distribution of income. American Economic Review, 62 (2), May 1972.

Some reflections on post-1964 Brazilian economic policy. In: Stepan, Alfred, ed. Authoritarian Brazil. New Haven, Yale University Press, 1973.

Who benefits from economic development? coment., American Economic Review, 70 (1), Mar. 1980.

Fox, M. Louise. Income distribution in Brazil: better numbers and new findings. Un. de Vanderbilt, 1982. Dissertação de Ph.D.

Gregory, Peter. Wage structures in Lat in America. Journal of Developing Areas, 8, July 1974.

Hewlitt, Sylvia A. The Cruel dilemmas of development: twentieth Century Brazil. New York, Basic Books, 1979.

Knight, Peter T. Brazilian socioeconomic development: issues for the eighties. World Development, 9 (11/12): 1.063-82, 1981.

\&Moran, Ricardo. Brazil: human resources special report, summary report. Relatório do Banco Mundial, no2.064-BR, julho 1979a.

Kuznets, Simon, Economic growth and income inequality. American Economic Review, 45 (1), Mar. 1955.

Langoni, Carlos Geraldo. Distribuição de renda e desenvolvimento econômico do Brasil. Rio de Janeiro, Expressão e Cultura, 1973.

Lluch, Constantino. On poverty and inequality in Brazil. Pesquisa e Planejamento Econômico, 11 (3), 757-82, dez. $1981 \mathrm{a}$ :

. On measures of income from censuses and the national accounts in Brazil. Documento de Tra- 
balho, Divisão de Emprego e Desenvolvimento Rural, Banco Mundial, set. $1981 b$.

Macedo, Roberto. A critical review of the relation between post-1964 wage policy and the worsening of Brazil's size income distribution in the 1960's. Explorations in Economic Research, 4 (1), Winter 1977.

Meesook, Oey Astra. Income distribution in Brazil. Universidade de Califórnia, 1972. Dissertação de Ph.D.

Morley, Samuel A.Growth and inequality in Brazil. LusoBrazilian Review, 15, Winter 1978.

The effect of changes in the population on several measures of income distribution. American Economic Review, 71 (4), June 1981.

. Labor Markets and inequalitable growth: the case of authoritarian capitalism in Brazil, Cambridge University Press, 1982 (no prelo).

\&Williamson, Jeffrey G. Growth, wage policy and inequality: Brazil during the sixties. SSRI Workshop Series, n? 7.519, Universidade de Wisconsin, July 1975 .

Payer, Cheryl. The Debt trap. Harmondsworth, Penguin, 1974.

Pffefermann, Guy \& Webb, Richard. The Distribution of income in Brazil. World Bank Staff, Documento de Trabalho n? 356, Washington, D.C., Banco Mundial, set. 1979.

Taylor, Lance, Bacha, Edmar; Cardoso, Eliana, \& Lysy, Frank J, Models of Growth and Distribution for Brazil. New York, Oxford University Press, 1980.

Williamson, Denise. Food prices and consumption comparisons Brasil 1975. Apr. 1981, mimeogr.
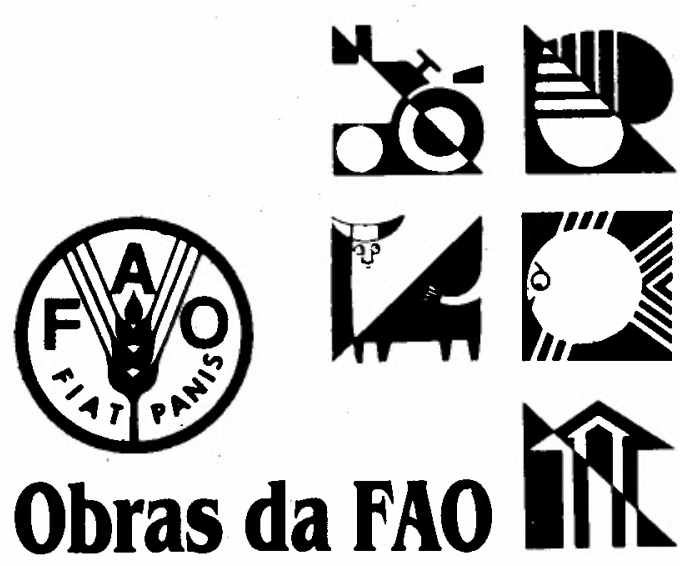

- Agricultura

- Produçao e proteçáo vegetal

- Produçáo e saúde animal

- Pesca

- Alimentaçāo e nutriçáo

- Desenvolvimento econômico e social

São alguns dos temas dos livros e periódicos da

Organização das Nações Unidas para a Agricultura

e Alimentação - FAO, agora também

na Fundação

Getulio Vargas.

Solicite catálogo.

Visite as livrarias da FGV.

E peça pelo Reembolso Postal à:

FGV/Editora

Divisão de Vendas

Caixa Postal 9052

20.000 - Rio de Janeiro - RJ 